\title{
Combining anterior and posterior component separation for extreme cases of abdominal wall reconstruction
}

\author{
J. Lopez-Monclus ${ }^{1}$ (1) J. Muñoz-Rodríguez ${ }^{2} \cdot$ C. San Miguel $^{2} \cdot$ A. Robin ${ }^{2} \cdot$ L. A. Blazquez ${ }^{3} \cdot$ M. Pérez-Flecha ${ }^{2}$. \\ N. Rupealta ${ }^{2} \cdot$ M. A. Garcia-Urena ${ }^{2} \mathbb{D}$
}

Received: 25 December 2019 / Accepted: 19 February 2020

(c) The Author(s) 2020, corrected publication 2020

\begin{abstract}
Purpose The closure of midline in abdominal wall incisional hernias is an essential principle. In some exceptional circumstances, despite adequate component separation techniques, this midline closure cannot be achieved. This study aims to review the results of using both anterior and component separation in these exceptional cases.

Methods We reviewed our experience using the combination of both anterior and posterior component separation in the attempt to close the midline. Our first step was to perform a TAR and a complete extensive dissection of the retromuscular preperitoneal plane developed laterally as far as the posterior axillary line. When the closure of midline was not possible, an external oblique release was made. A retromuscular preperitoneal reinforcement was made with the combination of an absorbable mesh and a $50 \times 50$ polypropylene mesh.

Results Twelve patients underwent anterior and posterior component separation. The mean hernia width was $23.5 \pm 5$. The majority were classified as severe complex incisional hernia and had previous attempts of repair. After a mean follow-up of 27 months (range 8-45), no case of recurrence was registered. Only one patient (8.33\%) presented with an asymptomatic bulging in the follow-up. European Hernia Society's quality of life scores showed a significant improvement at 2 years postoperatively in the three domains: pain $(p=0.01)$, restrictions $(p=0.04)$ and cosmetic $(p=0.01)$.

Conclusions The combination of posterior and anterior component separation can effectively treat massive and challenging cases of abdominal wall reconstruction in which the primary midline closure is impossible to achieve despite appropriate optimization of surgery.
\end{abstract}

Keywords Transversus abdominis release $\cdot$ Anterior component separation $\cdot$ Synthetic mesh $\cdot$ Complex hernia $\cdot$ Posterior component separation

\section{Introduction}

Incisional hernias (IH) are a frequent complication after midline laparotomies. A number of IH are considered complex because of size, location, domain loss, previous operations, the presence of stomas or infection, and comorbidities

\footnotetext{
M. A. Garcia-Urena

magurena@gmail.com

1 Henares University Hospital (Coslada, Madrid), Faculty of Health Sciences, Francisco de Vitoria University, Carretera Pozuelo-Majadahonda km. 1,800, 28223 Pozuelo de Alarcón, Spain

2 Puerta de Hierro University Hospital, Majadahonda, Madrid, Spain

3 Ramón y Cajal University Hospital, Madrid, Spain
}

$[1,2]$. The main goal of surgical repair of midline $\mathrm{IH}$ is to obtain a complete fascial approximation, with an appropriate mesh reinforcement.

However, some midline IH have extensive defects, thus for midline advancement of very widely separated borders, different component separation techniques have been described, and are divided into two groups: anterior component separation (ACS) and posterior component separation (PCS). Albanese first described ACS by releasing the insertion of external oblique muscles [3]. Ramirez implemented this technique in a cadaver study, which combined medial posterior rectus sheath release with external oblique detachment [4]. Later, this technique was effectively used with mesh reinforcement [5-7]. ACS generated advancements as long as $10 \mathrm{~cm}$. However, a main issue with this technique was morbidity associated with the wound, due to 
extensive subcutaneous detachment. To avoid these complications, modifications have been described for ACS, e.g. laparoscopic ACS and perforator preserving ACS $[8,9]$.

The PCS technique emerged only in the last decade; the approach facilitated closure of the midline with an extended lateral dissection, as in the previously described retromuscular preperitoneal plane [10]. The first PCS study was published in 2008, and described lengthening the lateral dissection between the internal oblique and transversus abdominis muscles [11]. After the initial publication of the transversus abdominis release (TAR) [12], this PCS approach spread rapidly among abdominal wall reconstruction (AWR) surgeons [6, 13-16], as it avoids subcutaneous dissection of ACS, and dissects a landing zone in a retromuscular position to lay the mesh as a reinforcement. The Madrid modification of the TAR was also implemented without a need for cutting the transversus abdominis (TA) muscle and reinserting the transversus muscle into the mesh [17].

In some challenging cases, despite using the component separation technique, there may still be difficulties in reintroducing the viscera and closing the midline. Also, abdominal closure may induce development of intra-abdominal hypertension and respiratory distress $[18,19]$. In these instances, quilted mesh, bridging repairs, or visceral resections have been performed $[16,20,21]$. Bridged repairs are associated with a high risk of recurrence [21]. In our experience, intestinal resection and anastomosis carry a risk of anastomotic dehiscence that may be fatal for the patient. Therefore, we decided to combine ACS and PCS for exceptional circumstances.

The aim of this study is to present data on TAR and ACS combinatorial approaches during exceptional and challenging cases, to achieve AWR.

\section{Materials and methods}

We performed a retrospective study on patients undergoing hernia repair at two specialized complex hernia repair centers, by reviewing a prospective AWR multicenter database. Patients undergoing AWR using a PCS approach, and those who also required an additional ACS for midline closure, where identified and reviewed. Ethical approval was obtained from the Institutional Review Board before study commencement. The report was written following the STROBE statement [22], and the recommendations for reporting outcomes in abdominal wall hernias [23].

All patients were evaluated in a multidisciplinary unit, specialized in abdominal wall procedures. Collected measures included age, sex, body mass index (BMI), comorbidities, type of hernia according to the European Hernia Society (EHS) classification, number of previous hernia repairs, and details of the initial operation. Surgical data included length of surgical procedures, width and length of the abdominal wall defect and other required surgical procedures (adhesiolysis, bowel resection, panniculectomy). In the postoperative period, any systemic complications or surgical site events were recorded, e.g. length of hospital stay.

All patients followed a similar preoperative optimization program, which included endocrinological and nutritional evaluations, smoking abstinence, weight loss and respiratory physiotherapy. Injection of botulinum toxin into the lateral abdominal wall musculature was performed under ultrasound guidance, approximately 4 weeks before surgery, as previously described [24]. This technique was applied to hernia defects longer than $10 \mathrm{~cm}$ width, started in 2017 . Progressive pneumoperitoneum, with daily insufflation of $500 \mathrm{ml}$ of air, was performed during the two weeks before surgery, for cases with $>25 \%$ Tanaka index [25].

\section{Surgical technique}

A schematic representation of the surgical technique is shown (Fig. 1). Under general anesthesia, the patient was placed in decubitus supinus, with a bladder catheter for intravesical pressure measurements, and an epidural catheter for pain management. The skin was incised through the previous scar, removing any unaesthetic scars, if present. If the patient had a large skin apron, the procedure was performed through a low transverse incision between both anterosuperior iliac spines, lifting all subcutaneous tissue until the epigastric area was reached. The hernia sac was opened longitudinally in two halves, and the bowel and omentum content were

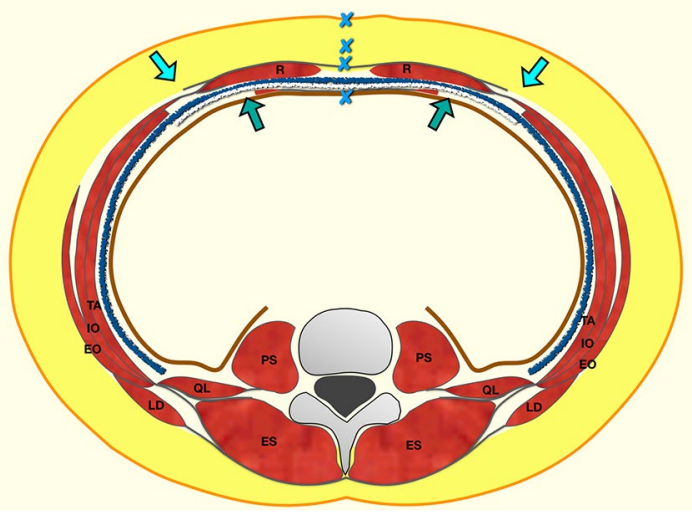

Fig. 1 Schematic representation of AWR with the combination of ACS and PCS. Absorbable mesh is depicted with a white line and polypropylene mesh with a blue line. The big synthetic mesh overlaps both weakened surfaces created by the external oblique and transversus abdominis releases. $E O$ external oblique muscle, $I O$ internal oblique muscle, $T A$ transversus abdominis muscle, $R$ rectus muscle, $P S$ psoas muscle, $Q L$ quadratus lumborum, $L D$ latissimus dorsi, $E S$ erector spinea muscles. Blue line: polypropylene mesh; white line: absorbable mesh; blue $\mathrm{X}$ : lines of sutures 
reduced. Half the hernia sac was left attached to the anterior rectus sheath, and the other half was left attached to the contralateral posterior rectus sheath. A meticulous adhesiolysis was performed if there were any adhesions to the hernia sac, or the parietal peritoneum. The abdominal content was then protected with a towel.

The posterior rectus sheath was opened bilaterally, and a retromuscular dissection was performed, reaching both the lateral borders of the posterior rectus sheath, as the lateral limit of the dissection. Perforator neurovascular bundles were visualized and carefully preserved. Midline cranial dissection was performed, raising the undamaged linea alba by cutting and pulling down both posterior rectus sheaths and preperitoneal fat in the midline, until the central tendon of the diaphragm is reached. Caudally, the retromuscular dissection was overextended to detect both the Cooper's ligaments. At this time of the surgery, two stitches of longterm absorbable monofilament (Monomax ${ }^{\circledR}$, USP 00, Mesh Elastic, B. Braun, Melsungen, Germany) were placed in both Cooper's ligaments to fix the permanent mesh later.

Then, a down to up TAR was performed, as previously described [17]. The created lateral retromuscular preperitoneal space was extended laterally as far as the posterior axillary line, reaching the quadratus lumborum and psoas muscle. Whenever possible, we aimed to cut the posterior rectus sheath more medially, cranially, to avoid transecting of the TA muscle fibers.

The posterior layer, comprising the posterior rectus sheath and part of the attached sac, was approximated with a running suture of a long-term absorbable monofilament not in all but one case, in which this closure could not be initially performed. In this case, after the initial attempt to reintroduce the abdominal content, there was a high peak of respiratory pressure. After the additional release of the external oblique muscle, the respiratory parameters improved, enabling posterior closure.

For mesh reinforcement, we used an absorbable posterior reinforcement of permanent mesh in a complex hernia (the Madrid Approach) [16]. According to, a piece of a $20 \times 30 \mathrm{~cm}$ absorbable mesh $\left(\mathrm{GORE}^{\circledR}\right.$ BIO-A ${ }^{\circledR}$ Tissue Reinforcement, WL Gore \& Associates, Inc. Flagstaff, AZ, USA) is placed over the posterior layer closure, to provide support for a large $50 \times 50 \mathrm{~cm}$ polypropylene macroporous mesh (Bulevb ${ }^{\circledR}$, Dipro Medical Devices SRL, Torino, Italy), which is fixed to the Cooper's ligaments. As required, one or two $15 \mathrm{~F}$ low-suction drains are placed over the mesh. The lateral border of the posterior rectus sheath is then reinserted into the permanent mesh, with running absorbable sutures.

At this point of the surgery, a first attempt to bring together the midline of the medial limits of the anterior rectus sheath is carried out. If closure of the anterior layer is impossible and the presence of an unacceptable gap according to the physical characteristic of the patient or in case of severe respiratory distress for the anesthesiologist, the decision to add an ACS is taken. The ACS is performed in two ways, depending on the initial approach. In cases where an extensive subcutaneous dissection has been performed (big and redundant subcutaneous sacs, with exposure of the anterior fascia further the lateral limit of the anterior rectus sheath, or an association of a panniculectomy), a fasciotomy is performed as described by Ramirez [4].

In case of no extensive lateral subcutaneous dissection, the ACS is performed in a minimally invasive open approach, as described [26]. Two $2 \mathrm{~cm}$ transverse skin incisions are performed at the point of the intersection of the umbilical line, and the mammarian line. The subcutaneous tissue is dissected until exposure of the external oblique aponeurosis. A small transverse incision is performed in this layer. With blunt blind dissection, the avascular space is dissected with the finger. A blind external oblique fasciotomy is performed, pushing partially closed long scissors in the cranial and caudal border of the aponeurosis opening, reaching both the costal margin and the inguinal ligament.

Once the ACS has been performed, the midline is closed with a running suture of long-term absorbable monofilament (Monomax $^{\circledR}$, USP 1 or O, Mesh Elastic, B.Braun, Melsungen, Germany). In case complete closure is not possible despite addition of ACS and PCS, the gap is bridged over the mesh, suturing the border of the anterior rectus sheath to the polypropylene mesh, with running sutures of long-term absorbable monofilaments (Monomax ${ }^{\circledR}$, USP 00, Mesh Elastic, B.Braun, Melsungen, Germany). To isolate the exposed mesh from subcutaneous tissue, part of the hernia sac that remains attached to the anterior rectus sheath is sutured to the contralateral border of the posterior rectus sheath, with full coverage of the bridged mesh. After closure of the anterior layer, one or two low-suction drains are placed in the subcutaneous space, in case of an associated panniculectomy. The subcutaneous tissue is sutured with short-term absorbable stitches, and the skin is closed with staples.

\section{Follow-up}

Follow-up evaluations consisted of a physical examination in the outpatient clinic at 4-5 weeks, 3 months, 6 months, 1 year, and then annually thereafter. Patients underwent an abdominal computed tomography (CT) scan in case of clinical doubts, or as part of oncological surveillance.

Long-term complications such as chronic pain, chronic mesh infection, recurrence, and bulging were evaluated at each visit. Recurrence was defined as a new abdominal wall defect in the operated area, as identified by physical examination or imaging. Bulging was defined as an area of weakness or asymmetry during patient abdominal wall inspection or exploration, without any solution of continuity in 
the abdominal wall visible by CT. We used the European Abdominal Wall Hernia Quality of Life Scores (EuraHSQoL) to compare evolution in patients by pain, restriction and cosmetic domains between the preoperative and postoperative periods [27].

\section{Statistics}

Variable descriptions and statistical analyses were performed using the Statistical Package for the Social Sciences (SPSS) program (version 19.0 for Windows). In an intention to perform the analysis, quantitative variables were expressed as the mean/median and standard deviation/quartiles, and categorical variables were expressed as absolute numbers and percentages. Spearman's correlation coefficient was used to measure the strength of relationship between paired data of EuraHS-QoL scores.

\section{Results}

\section{Patient demographics and characteristics}

Between 2014 and 2019, 12 patients who underwent AWR, required combined PCS and ACS. Patient demographics and characteristics are shown (Table 1). The mean age was $62.66 \pm 11.8$ years, and the mean BMI was $37.19 \pm 7.94 \mathrm{~kg} /$ $\mathrm{m}^{2}$. Eight patients had a previous history of incisional hernia repair.

\section{Hernia characteristics}

Hernia features are summarized in Table 2 . The mean width of the horizontal aponeurotic defect was $23.58 \pm 4.91 \mathrm{~cm}$, and the mean vertical length was $19.91 \pm 5.50 \mathrm{~cm}$. All defects were midline, ten (83.3\%) were M1-M5 according to EHS classification, and two (16.7\%) presented a concomitant lateral incisional hernia.

\section{Operative details}

Operative details are presented (Table 3 ). In seven cases $(58.33 \%)$, preoperative pneumoperitoneum was performed with a median of $11.800 \mathrm{ml}(5.000-12.000 \mathrm{ml})$ air. Botulin toxin injection was used in five cases $(41.66 \%)$. Ten cases $(83.33 \%)$ were classified as clean and clean-contaminated wounds. The posterior layer could be closed in all cases. Three patients (25\%) required an anterior layer bridge, without the possibility of complete closure of the midline, with a mean horizontal bridge of $2.9 \mathrm{~cm}$, and a mean vertical bridge of $3 \mathrm{~cm}$. There was a 25\% rate of enterotomies; all initially repaired. Associated surgeries included; omentum
Table 1 Demographics and characteristics of patients

\begin{tabular}{|c|c|}
\hline Variables & $N(\%)$ \\
\hline \multicolumn{2}{|l|}{ Sex } \\
\hline Male & $5(41.7 \%)$ \\
\hline Female & $7(58.3 \%)$ \\
\hline Age, mean $\pm \mathrm{DS}$ & $62.66 \pm 11.8$ \\
\hline $\mathrm{BMI}^{\mathrm{a}}$, mean $\pm \mathrm{DS}$ & $37.19 \pm 7.94$ \\
\hline Obesity (BMI > 30) & $10(83.33 \%)$ \\
\hline \multicolumn{2}{|l|}{ Comorbidities } \\
\hline $\begin{array}{l}\text { Smoking } \\
\text { Anticoagulation } \\
\text { Diabetes } \\
\text { Immunosuppression } \\
\text { COPD }^{\mathrm{b}} \\
\text { Hypertension } \\
\text { Neoplasia } \\
\text { Cardiac disease }\end{array}$ & $\begin{array}{l}0(0 \%) \\
0(0 \%) \\
4(33.3 \%) \\
1(8.3 \%) \\
5(41.7 \%) \\
6(50 \%) \\
6(50 \%) \\
1(8.3 \%)\end{array}$ \\
\hline $\mathrm{CeDAR}^{\mathrm{c}} ;$ mean $\pm \mathrm{DS}$ & $48.66 \pm 17.44$ \\
\hline $\begin{array}{l}<30 \% \\
30-60 \% \\
>60 \%\end{array}$ & $\begin{array}{l}2(16.7 \%) \\
7(58.33 \%) \\
3(25 \%)\end{array}$ \\
\hline \multicolumn{2}{|l|}{$\mathrm{ASA}^{\mathrm{d}}$} \\
\hline $\begin{array}{l}\text { I } \\
\text { II } \\
\text { III } \\
\text { IV }\end{array}$ & $\begin{array}{l}1(8.3 \%) \\
6(50 \%) \\
5(41.7 \%) \\
0(0 \%)\end{array}$ \\
\hline Recurrent & $8(66.6 \%)$ \\
\hline 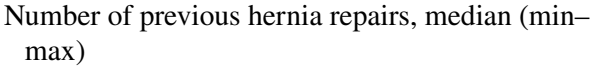 & $2(0-5)$ \\
\hline \multicolumn{2}{|l|}{ Etiology of main IH } \\
\hline $\begin{array}{l}\text { Digestive tube } \\
\text { Urology } \\
\text { Gynecology and obstetrics } \\
\text { Others }\end{array}$ & $\begin{array}{l}6(50 \%) \\
2(16.7 \%) \\
2(16.7 \%) \\
2(16.7 \%)\end{array}$ \\
\hline
\end{tabular}

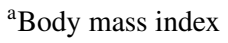

${ }^{\mathrm{b}}$ Chronic obstructive pulmonary disease

${ }^{\mathrm{c}}$ Carolinas equation for determining associated risks

${ }^{\mathrm{d}}$ American society of anesthesiologists

resection for two cases (16.7\%), and in nine cases (75\%), a panniculectomy was performed as part of the AWR.

\section{Postoperative complications}

Postoperative complications are summarized (Table 4). Surgical site infections (SSI) were reported in four cases (33.3\%): superficial SSI in two patients (16.7\%), deep SSI in two cases (16.7\%), and no organ/space SSI was registered. The overall incidence of surgical site occurrences (SSO) was $66.6 \%$. Seven cases $(58.3 \%$ ) developed a seroma in the first 30 postoperative days. In $25 \%$ of patients, a skin/wound dehiscence was registered. There were five SSO (41.7\%) that required procedural interventions (SSOPI): four bed-side drains, and one chronic seroma that required reintervention 
Table 2 Characteristics of IH

\begin{tabular}{ll}
\hline & $N(\%)$ \\
\hline EHS classification of main IH & \\
Midline & $12(100 \%)$ \\
M1-M5 & $10(83.33 \%)$ \\
M3-M5 & $2(16.7 \%)$ \\
EHS classification of associated IH & \\
Lateral & $2(16.7 \%)$ \\
L3 & $2(16.7 \%)$ \\
Maximum horizontal size cm; mean \pm DS & $23.58 \pm 4.91$ \\
Maximum vertical size cm; mean \pm DS & $19.91 \pm 5.50$ \\
W EHS & \\
W1 $(<4$ cm) & $0(0 \%)$ \\
W2 (4-10 cm) & $0(0 \%)$ \\
W3 (> 10 cm) & $12(100 \%)$ \\
Slater's classification & \\
Grade 1 & $0(0 \%)$ \\
Grade 2 & $4(33.3 \%)$ \\
Grade 3 & $8(66.7 \%)$ \\
VHWG ${ }^{\text {c classification }}$ & \\
Grade 1 & $1(8.3 \%)$ \\
Grade 2 & $10(83.3 \%)$ \\
Grade 3 & $1(8.3 \%)$ \\
Grade 4 & $0(0 \%)$ \\
Grade 1 & \\
Grade 2 & \\
Grade 3 & $0(0 \%)$ \\
\hline & $3(25 \%)$ \\
Ventafication & $9(75 \%)$ \\
\hline
\end{tabular}

${ }^{a}$ Ventral hernia working group hernia classification

${ }^{\mathrm{b}}$ Ventral hernia staging system classification

Table 3 Operative data

\begin{tabular}{ll}
\hline Variables & $N(\%)$ \\
\hline Wound classification [43] & \\
Clean & $9(75 \%)$ \\
Clean-contaminated & $1(8.3 \%)$ \\
Contaminated & $2(16.7 \%)$ \\
Dirty & $0(0 \%)$ \\
Bridging of posterior layer & $0(0 \%)$ \\
Bridging of anterior layer & $3(25 \%)$ \\
Maximum diameter of bridging; mean (min-max) & \\
Horizontal & $2.9(0-7)$ \\
Vertical & $3(0-8)$ \\
Associated surgery for the IH repair & \\
Adhesiolysis & $7(58.3 \%)$ \\
Omentum resection & $2(16.7 \%)$ \\
Closure of bowel opening & $3(25 \%)$ \\
Panniculectomy & $9(75 \%)$ \\
Operative time (min), mean \pm DS & $339.16 \pm 66.18$ \\
\hline
\end{tabular}

with a talc seromadesis (28). In terms of systemic complications, there were three cases (25\%) of pneumonia with an associated respiratory insufficiency, and one case required intensive care. No postoperative mortalities were registered. No patient developed intra-abdominal hypertension.

\section{Long-term postoperative complications}

Long-term postoperative complications are shown (Table 5). After a mean follow-up of 27 months (range 8-45), no recurrences were registered. Only one patient $(8.33 \%)$ presented with an asymptomatic bulging at follow-up. No cases of chronic pain or chronic mesh infection were identified. No mortalities were recorded during follow-up.

\section{Quality Of Life}

EuraHS-QoL scores over time are shown (Figs. 2, 3, 4). The differences were statistically significant between preoperative and 1-year scores for pain ( $p=0.05$; moderate correlation) and restriction ( $p=0.01$; very strong correlation) domains. The difference was also was statistically significant in all three domains between 1 and 2 postoperative years (pain, $p=0.01$; restriction, $p=0.04$; cosmetic, $p=0.01$; very strong correlation).

\section{Discussion}

This study described the association of ACS and PCS techniques for AWR, in exceptional surgical circumstances. The impossibility of closing posterior or anterior layers were the two main reasons for adding the detachment of the external oblique muscle to the TAR (Table 6). In our experience, after the lateral incision on the posterior rectus sheath, we perform an extended dissection in the retromuscular preperitoneal plane from the central tendon of the diaphragm to the Cooper's ligaments, and from the psoas-quadratum lumborum of one side, to the contralateral homonymous muscles. However, despite this extensive dissection and patient optimization with botulinum injections and pneumoperitoneum, the impossibility of closing the posterior layer, composed of the remaining peritoneal sac and posterior rectus sheath, may occur. This situation may result from a lack or obliteration of these layers because of previous surgeries, scarred tissue or previous mesh infections. In these circumstances, the use of omentum, or absorbable meshes have been described [16, $29,30]$. When the viscera cannot be returned to the abdomen, another surgical possibility is to reduce intra-abdominal volume by resection, in the following order, omentum, retroperitoneal lipomatosis or right hemicolectomy [31]. However, this last resection may lead to a postoperative 
Table 4 Postoperative complications

\begin{tabular}{|c|c|c|}
\hline Variable & $N(\%)$ & Clavien-Dindo \\
\hline \multicolumn{3}{|l|}{ SSO } \\
\hline Any SSO & $8(66.66 \%)$ & \\
\hline SSOPI & $5(41.7 \%)$ & \\
\hline SSI & $4(33.3 \%)$ & \\
\hline $\begin{array}{l}\text { Superficial } \\
\text { Deep } \\
\text { Organ/space }\end{array}$ & $\begin{array}{l}2(16.7 \%) \\
2(16.7 \%) \\
0(0 \%)\end{array}$ & $\begin{array}{l}\text { Grade I: } 2(16.7 \%) \text { bed-side treatments } \\
\text { Grade II: } 2(16.7 \%) \text { antibiotics + bed-side treatments }\end{array}$ \\
\hline Hematoma & $0(0 \%)$ & \\
\hline Seroma & $7(58.3 \%)$ & $\begin{array}{l}\text { Grade II: } 4(33.3 \%) \text { bed-side treatments + antibiotics treatment. Grade IIIb: } 1 \\
\text { reintervention }\end{array}$ \\
\hline $\begin{array}{l}\text { Skin/wound dehiscence } \\
\text { Fascial disruption }\end{array}$ & $\begin{array}{l}3(25 \%) \\
0(0 \%)\end{array}$ & Grade I: $3(25 \%)$ \\
\hline \multicolumn{3}{|l|}{ Abdominal complications } \\
\hline $\begin{array}{l}\text { Paralytic ileus } \\
\text { Anastomotic dehiscence }\end{array}$ & $\begin{array}{l}1(8.3 \%) \\
0(0 \%)\end{array}$ & Grade I: $1(8.3 \%)$ conservative treatment \\
\hline \multicolumn{3}{|l|}{ Systemic complications } \\
\hline Urinary infection & $4(33.3 \%)$ & Grade II: 4 (33.3\%) antibiotics treatment \\
\hline $\begin{array}{l}\text { Venous line infection } \\
\text { Respiratory insufficiency }\end{array}$ & $\begin{array}{l}3(25 \%) \\
3(25 \%)\end{array}$ & $\begin{array}{l}\text { Grade I: } 3(125 \%) \text { removal of cathether } \\
\text { Grade II: } 2(16.7 \%) \text { : antibiotics treatment. Grade IVa: } 1(8.3 \%) \text { intensive care }\end{array}$ \\
\hline Renal insufficiency & $0(0 \%)$ & \\
\hline Pneumonia & $3(25 \%)$ & Grade II: 2 (16.7\%): antibiotics treatment. Grade IVa: $1(8.3 \%)$ Intensive care \\
\hline 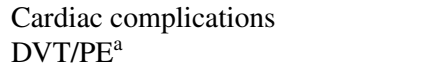 & $\begin{array}{l}1(8.3 \%) \\
0(0 \%)\end{array}$ & Grade I: $1(8.3 \%)$ diuretic treatment \\
\hline Pain $>48 \mathrm{~h}$ requiring opioids & $8(66.7 \%)$ & \\
\hline $\begin{array}{l}\text { Length of hospitalization, median, } \\
(\min -\max )\end{array}$ & $7(1-54)$ & \\
\hline 30 day mortality & $0(0 \%)$ & \\
\hline Readmission & $3(25 \%)$ & \\
\hline
\end{tabular}

${ }^{\text {a }}$ Deep venous thrombosis/pulmonary thromboembolism; $\alpha$ Intensive care unit

Table 5 Long-term postoperative complications

\begin{tabular}{ll}
\hline Variables & $N(\%)$ \\
\hline Clinical recurrence & $0(0 \%)$ \\
CT control & \\
No CT performed & $5(41.7 \%)$ \\
No CT recurrence & $7(58.3 \%)$ \\
Yes CT recurrence & $0(0 \%)$ \\
Mesh infection & $1(0.8 \%)$ \\
Pain & \\
Discomfort & $5(41.7 \%)$ \\
Occasional need for pain treatment & $1(8.3 \%)$ \\
Daily treatment for pain & $0(0 \%)$ \\
Interventional treatment for pain; no pain & $0(0 \%)$ \\
Bulging & \\
No bulging & $11(91.7 \%)$ \\
Asymptomatic bulging & $1(8.3 \%)$ \\
Reoperation for recurrence or bulging & $0(0 \%)$ \\
\hline
\end{tabular}

anastomotic dehiscence, in a potentially increased abdominal pressure environment that could be disastrous. To prevent this risk, adding an external oblique muscle release to the TAR could be a possibility in some extreme cases, as observed in one of our patients. In this case, the return of abdominal content before completely closing posterior layer resulted in an increased in abdominal pressure and respiratory parameters. The addition of an external oblique release provided enough volume, improving the respiratory parameters.

The other surgical possibility after a TAR in challenging situations, is the impossibility of closing the anterior layer (linea alba). This layer usually consists of the rest of a retracted anterior aponeurosis of the rectus sheath that cannot be approximated. There are several reasons why a surgeon cannot perform closure of an anterior layer, despite a proper TAR (Table 6). Previous scars, infected meshes and the massive size of the defect could make it mechanically impossible to close. Also, too much tension on the abdomen may cause intra-abdominal hypertension or respiratory insufficiency. 
Fig. 2 The evolution over time of EuraHS-QoL of pain domain is shown

Fig. 3 The evolution over time of EuraHS-QoL of restrictions domain is shown

Fig. 4 The evolution over time of EuraHS-QoL of cosmetic domain of is shown
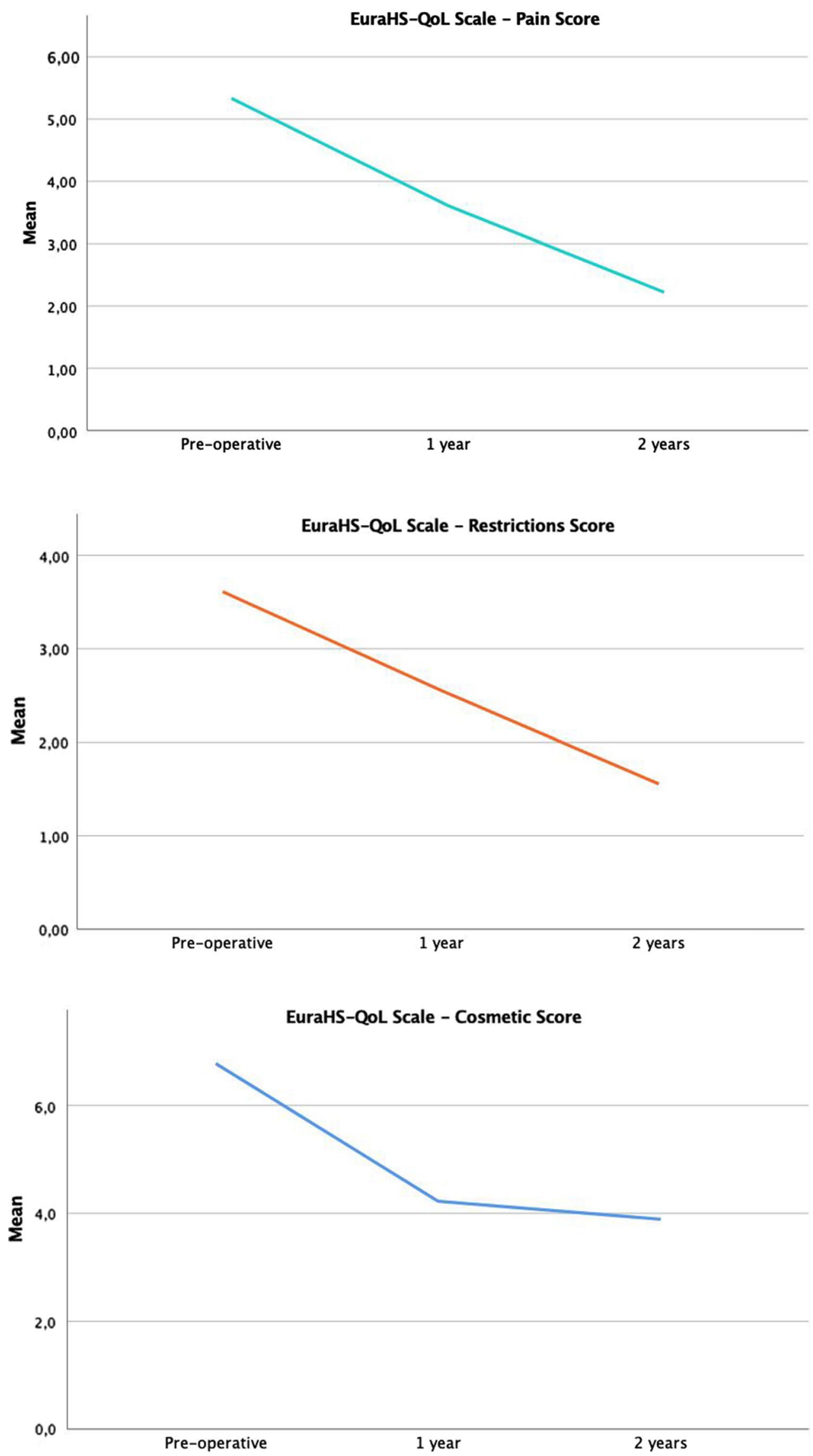
Table 6 Possible surgical solutions when midline cannot be completely closed after a TAR

\begin{tabular}{ll}
\hline & Possible surgical solutions \\
\hline Reasons for not closing posterior layer ${ }^{\mathrm{a}}$ & \\
Lack or obliteration of layer, mesh removals & $\begin{array}{l}\text { Omentum interposition [29] } \\
\text { Bridge with absorbable mesh [30] } \\
\text { Visceral resection [31] }\end{array}$ \\
Impossibility of viscera to return to the abdominal cavity & External oblique release (present series) \\
Intra-abdominal hypertension & \\
Non tolerated increase of respiratory pressures & \\
Reasons for not closing anterior layer ${ }^{\text {b }}$ & \\
Lack or obliteration of layer, mesh removals & Visceral resection [31] \\
Scarred tissues, fibrosis, retracted muscles with very wide gap & Myofascial flaps [32] \\
Intra-abdominal hypertension & Abdominal wall transplant [33] \\
Non tolerated increase of respiratory pressures & Abdominal wall expanding system [35] \\
& Bridged repair [21] \\
& External oblique release (present series) \\
& Staged procedure [36] \\
\hline
\end{tabular}

${ }^{\text {a }}$ Posterior layer is considered the rest of posterior rectus sheath and peritoneum on both sides of the abdomen

${ }^{\mathrm{b}}$ Anterior layer is the anterior rectus sheath that insert on linea alba on both sides of the abdomen
Surgical solutions have been described to deal with these conditions: myofascial flaps, abdominal wall transplants, abdominal wall expanding systems, bridged repairs, staged repairs and in this study, adding an ACS to a PCS. Myofascial flaps have been used for AWR to cover significant defects in the abdomen and skin [32]. However, we agree that pedical or free flaps only provide soft tissue coverage of the intra-abdominal content [21]. Abdominal wall transplantation may also offer viscera protection, however, these procedures are complicated and involve immunosuppression therapy that impairs wound healing, and may facilitate infection and other long-term side effects [33]. The use of an abdominal wall expanding system has also been proposed in reducing, intraoperatively, the distance of the fascial defect, $[34,35]$. There is very limited experience in this method. Another possibility is to perform a temporary abdominal wall closure, using a mesh that is progressively excised to allow definite closure of the abdomen with a component separation [36]. In this initial report of staged repair, an average of six interval operations were necessary before the final operation. We consider that this staged surgery could be an option when increases in intra-abdominal pressure or respiratory insufficiency are primary concerns.

The other possibility is the use of a bridged repair after the TAR, as previously described [16, 20, 21, 37]. When a TAR is performed, and the anterior layer is not entirely closed, synthetic mesh is secured at the edges of the anterior layer. In a recent study of 77 patients with bridged repairs, patient-reported outcomes were favorable [21]. However, these authors also described a very high recurrence rate of nearly $50 \%$. High incidences of recurrences have also been reported when bridging with biological meshes [38, 39]. Therefore, we advocate full reconstruction of the midline as a relevant component in complex AWR. This poses the question; what approach is ideal in these challenging cases? A TAR with a bridged repair or a TAR adding an ACS? The answer will depend on the size and location of the surface to be bridged.

Combining external oblique muscles and TAR is considered dangerous, because of the potential instability to the abdominal wall, as the only lateral muscle that remains anatomically attached to its anatomical insertions is the internal oblique muscle. However, some anatomical concepts require thoughtful review. Despite the TAR, the TA muscle still maintains its attachment to the internal oblique muscle all along its surface and, inferiorly, it also contributes to the anterior rectus sheath below the linea arcuata. In the TAR, we only release the transversus abdominis from its anatomical insertion in the posterior rectus sheath. After the TAR, we do not observe the retraction of the TA muscle that is developed when the external oblique is released, due to the strong interconnections between the internal oblique and transversus where the neurovascular bundles from the intercostal nerves are coming. Also, the size of the synthetic mesh we currently use in the TAR, overlaps the release of the external oblique muscle and this way, we cover the possibility of a subsequent defect or bulging in that area (Fig. 1). Furthermore, it is possible to reinsert the TA muscle into the synthetic mesh, to avoid the partial disconnection of the TA [17]. It must be remembered that positive results were published for TAR after recurrences of ACS techniques [13]. In a recent report, 29 patients were treated with a combination of ACS and PCS by the release of external oblique muscle through a debatable posterior access between neurovascular bundles [40].

We do not want to encourage surgeons to perform ACS and PCS combinations, but surgical possibilities under challenging settings must be debated. There is no need 

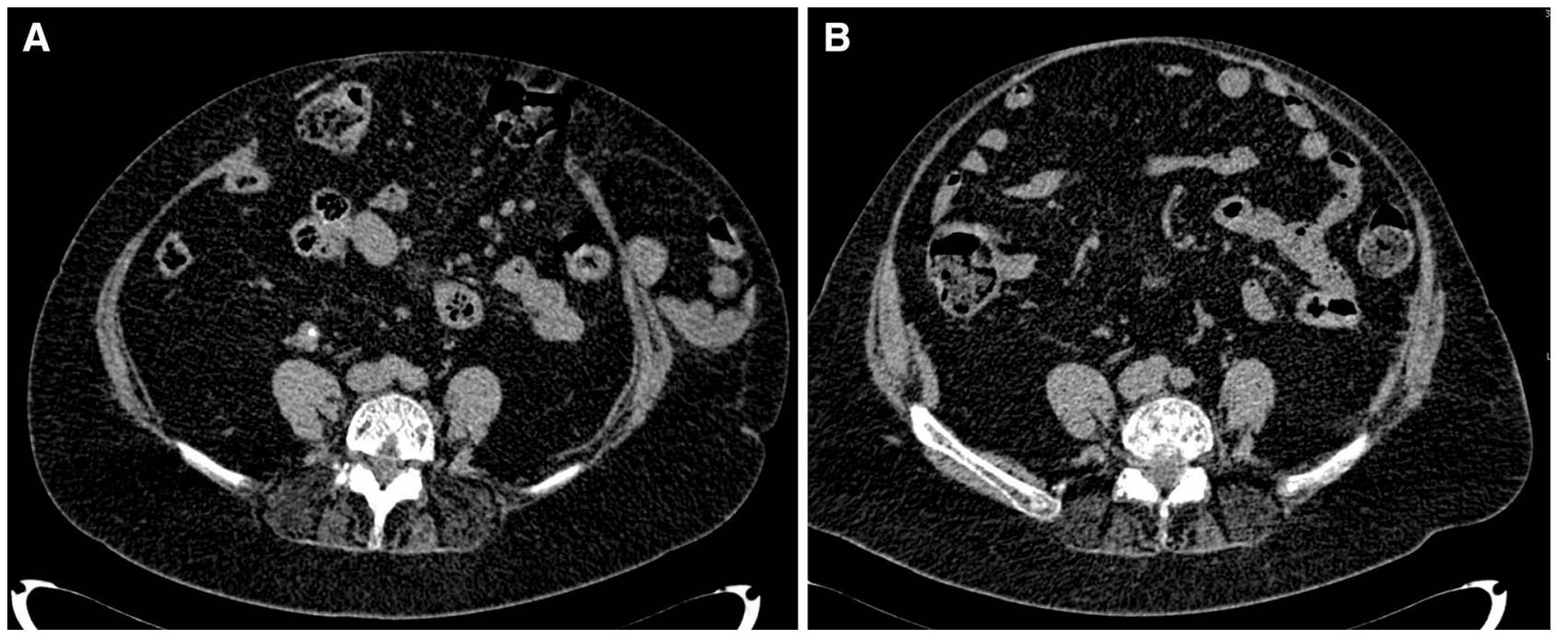

Fig. 5 a Preoperative CT scan of an old lady with a midline defect $30 \mathrm{~cm}$ long and maximum $20 \mathrm{~cm}$ width. b Control CT scan in Valsalva at 18 postoperative months of the patient a after AWR with the combination of TAR and external oblique release. A weak but continent abdominal wall is observed
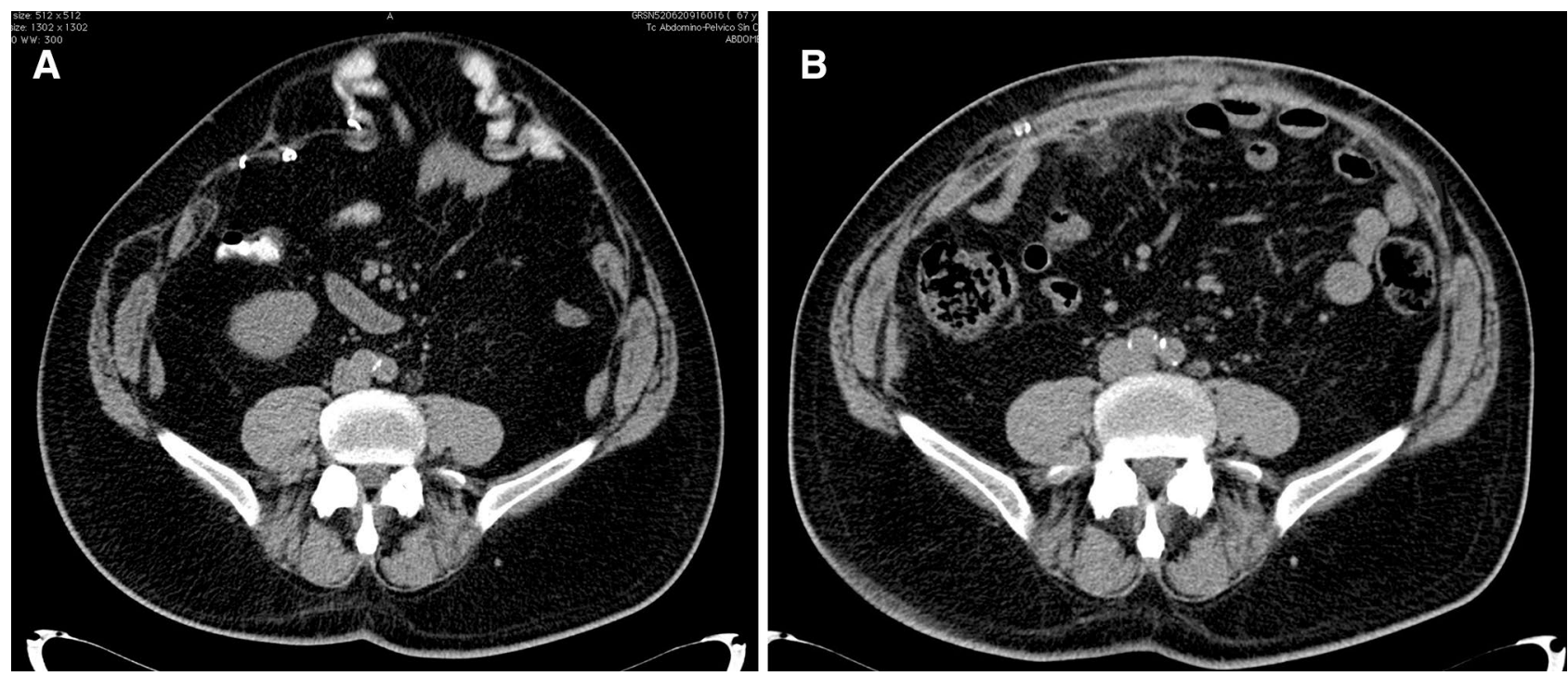

Fig. 6 a Preoperative CT scan of a 58 years old man with a midline defect $28 \mathrm{~cm}$ long and maximum $22 \mathrm{~cm}$ width. b Control CT scan without Valsalva at 4 postoperative months of the patient a after AWR with the combination of TAR and external oblique release

to remember the exceptional circumstances of this cohort of patients that associate severe comorbidities, multiple recurrences, big size of defects, and loss of domain (Figs. 5, 6). When dealing with these situations, the main objective of AWR is to provide abdominal wall continence. Combining ACS and TAR may provide closure of the abdomen and restore the connection between both sides of the abdominal wall. This continence was reflected by satisfactory patient-reported outcomes in our study. This objective was particularly achieved for the youngest patient in our cohort, as he is now playing regular sports, after his AWR. In our opinion, these difficult cases should be treated in dedicated centers of AWR with enough level of expertise.

In our cohort, associated wound morbidity was high. It is superior to our reported outcomes of AWR [16], and those from the largest series of TAR [14]. We do not get lower SSO and SSOPI published in similar larger series [21], despite adequate patient optimization. The only difference in our cohort was that we had significantly more patients with panniculectomy, which could partially explain our higher morbidity. Although it is a short cohort of patients, the 
long-term results obtained and the positive patient-reported outcomes are encouraging.

\section{Study limitations}

Our study had limitations. With our small number of cases, it was difficult to draw definitive conclusions on the management of these highly complex repairs. We have not made comparisons with other surgical options, or other conservative non-operating approaches. However, a prospective group for comparison will be difficult, as the circumstances and etiopathogenesis that generate these complicated abdominal wall defects are infrequent and variable. Although all patients were followed-up clinically, a control CT scan was made available in only $66 \%$ of patients; therefore, a radiological recurrence could have been clinically missed. Although we have a mean follow-up of more than 2 years, a longer follow-up would be ideal in confirming surgical durability and stability.

In conclusion, combining external oblique release with TAR may be considered a surgical alternative in addressing demanding surgical situations, where defect complexity and patient characteristics do not allow complete midline reconstruction. While the approach is associated with high morbidity and a long hospital recovery, long-term results and patient-reported outcomes are reassuring.

\section{Compliance with ethical standards}

Conflict of interest Dr. Garcia-Urena reports grants to attend Congress and personal fees from Gore regarding proctorships and workshops in AWR, and personal fees as invited speaker from Dipro, both, outside the submitted work. Dr. Lopez-Monclus reports personal fees from Gore regarding proctorships and workshops in AWR, outside the submitted work. Dr. Blazquez, Dr. Robin and Dr. San Miguel report personal fees from Gore regarding workshops in AWR, outside the submitted work. Dr. Perez-Flecha, Dr. Muñoz and Dr. Rupealta report no conflict of interest.

Ethical approval This study was reviewed and approved by the Francisco de Vitoria University Ethics Committee (39/2019).

Human and animal rights This article does not contain any studies directly involving human participants, as it is a review of data already collected in hernia database.

Informed consent For this type of retrospective study, formal specific consent was not necessary. All patients received informed consent about the operative procedures.

Open Access This article is licensed under a Creative Commons Attribution 4.0 International License, which permits use, sharing, adaptation, distribution and reproduction in any medium or format, as long as you give appropriate credit to the original author(s) and the source, provide a link to the Creative Commons licence, and indicate if changes were made. The images or other third party material in this article are included in the article's Creative Commons licence, unless indicated otherwise in a credit line to the material. If material is not included in the article's Creative Commons licence and your intended use is not permitted by statutory regulation or exceeds the permitted use, you will need to obtain permission directly from the copyright holder. To view a copy of this licence, visit http://creativecommons.org/licenses/by/4.0/.

\section{References}

1. Ventral Hernia Working G, Breuing K, Butler CE, Ferzoco S, Franz M, Hultman CS et al (2010) Incisional ventral hernias: review of the literature and recommendations regarding the grading and technique of repair. Surgery 148(3):544-558

2. Slater NJ, Montgomery A, Berrevoet F, Carbonell AM, Chang A, Franklin $\mathrm{M}$ et al (2014) Criteria for definition of a complex abdominal wall hernia. Hernia 18(1):7-17

3. Albanese AR (1951) Gigantic median xipho-umbilical eventration; method for treatment. Rev Asoc Med Argent 65(709-710):376-378

4. Ramirez OM, Ruas E, Dellon AL (1990) "Components separation" method for closure of abdominal-wall defects: an anatomic and clinical study. Plast Reconstr Surg 86(3):519-526

5. de Vries Reilingh TS, van GH, Charbon JA, Rosman C, Hesselink EJ, van der Wilt GJ et al (2007) Repair of giant midline abdominal wall hernias: "components separation technique" versus prosthetic repair : interim analysis of a randomized controlled trial. World $\mathrm{J}$ Surg 31(4):756-763

6. Cornette B, De Bacquer D, Berrevoet F (2018) Component separation technique for giant incisional hernia: a systematic review. Am J Surg 215(4):719-726

7. Torregrosa-Gallud A, Sancho Muriel J, Bueno-Lledó J, García Pastor P, Iserte-Hernandez J, Bonafé-Diana S et al (2017) Modified components separation technique: experience treating large, complex ventral hernias at a University Hospital. Hernia 21(4):601-608

8. Rosen MJ, Jin J, McGee MF, Williams C, Marks J, Ponsky JL (2007) Laparoscopic component separation in the single-stage treatment of infected abdominal wall prosthetic removal. Hernia 11(5):435-440

9. Ghali S, Turza KC, Baumann DP, Butler CE (2012) Minimally invasive component separation results in fewer wound-healing complications than open component separation for large ventral hernia repairs. J Am Coll Surg 214(6):981-989

10. Novitsky YW, Porter JR, Rucho ZC, Getz SB, Pratt BL, Kercher $\mathrm{KW}$ et al (2006) Open preperitoneal retrofascial mesh repair for multiply recurrent ventral incisional hernias. J Am Coll Surg 203(3):283-289

11 Carbonell AM, Cobb WS, Chen SM (2008) Posterior components separation during retromuscular hernia repair. Hernia 12(4):359-362

12. Novitsky YW, Elliott HL, Orenstein SB, Rosen MJ (2012) Transversus abdominis muscle release: a novel approach to posterior component separation during complex abdominal wall reconstruction. Am J Surg 204(5):709-716

13. Pauli EM, Wang J, Petro CC, Juza RM, Novitsky YW, Rosen MJ (2015) Posterior component separation with transversus abdominis release successfully addresses recurrent ventral hernias following anterior component separation. Hernia 19(2):285-291

14. Novitsky YW, Fayezizadeh M, Majumder A, Neupane R, Elliott HL, Orenstein SB (2016) Outcomes of posterior component separation with transversus abdominis muscle release and synthetic mesh sublay reinforcement. Ann Surg 264(2):226-232 
15. Appleton ND, Anderson KD, Hancock K, Scott MH, Walsh CJ (2017) Initial UK experience with transversus abdominis muscle release for posterior components separation in abdominal wall reconstruction of large or complex ventral hernias: a combined approach by general and plastic surgeons. Ann R Coll Surg Engl 99(4):265-270

16. García-Ureña M, López-Monclús J, Cuccurullo D, Blázquez Hernando LA, García-Pastor P, Reggio S et al (2018) Abdominal wall reconstruction utilizing the combination of absorbable and permanent mesh in a retromuscular position: a multicenter prospective study. World J Surg 43(1):149-158

17. Robin-Lersundi A, Blazquez Hernando L, López-Monclús J, Cruz Cidoncha A, San Miguel Méndez C, Jimenez Cubedo E et al (2018) How we do it: down to up posterior components separation. Langenbecks Arch Surg 403(4):539-546

18. Pierri A, Munegato G, Carraro L, Zaccaria F, Tiso E, Zotti EF (1995) Hemodynamic alterations during massive incisional hernioplasty. J Am Coll Surg 181(4):299-302

19. Munegato G, Brandolese R (2001) Respiratory physiopathology in surgical repair for large incisional hernias of the abdominal wall. J Am Coll Surg 192(3):298-304

20. Posielski NM, Yee ST, Majumder A, Orenstein SB, Prabhu AS, Novitsky YW (2015) Repair of massive ventral hernias with "quilted" mesh. Hernia 19(3):465-472

21. Alkhatib H, Tastaldi L, Krpata DM, Petro CC, Fafaj A, Rosenblatt $S$ et al (2019) Outcomes of transversus abdominis release (TAR) with permanent synthetic retromuscular reinforcement for bridged repairs in massive ventral hernias: a retrospective review. Hernia. https://www.ncbi.nlm.nih.gov/pubmed/31549325

22. von Elm E, Altman DG, Egger M, Pocock SJ, Gotzsche PC, Vandenbroucke JP et al (2007) The strengthening the reporting of observational studies in epidemiology (STROBE) statement: guidelines for reporting observational studies. Ann Intern Med 147(8):573-577

23. Muysoms FE, Deerenberg EB, Peeters E, Agresta F, Berrevoet F, Campanelli G et al (2013) Recommendations for reporting outcome results in abdominal wall repair: results of a consensus meeting in Palermo, Italy, 28-30 June 2012. Hernia 17(4):423-433

24. Ibarra-Hurtado TR, Nuño-Guzmán CM, Echeagaray-Herrera JE, Robles-Vélez E, de Jesús G-J (2009) Use of botulinum toxin type a before abdominal wall hernia reconstruction. World J Surg 33(12):2553-2556

25. Tanaka EY, Yoo JH, Rodrigues AJ, Utiyama EM, Birolini D, Rasslan S (2010) A computerized tomography scan method for calculating the hernia sac and abdominal cavity volume in complex large incisional hernia with loss of domain. Hernia 14(1):63-69

26. Dumanian AG (2016) Periumbilical perforator sparing component separation. In: Rosen MJ (ed) Abdominal wall reconstruction, 2nd edn. Elsevier, Philadelphia, pp 166-180

27. European Hernia Society EH (2019) EuraHS—European Registry of abdominal wall HerniaslEuraHS quality of life score. https://
www.eurahs.eu/EuraHS-Quality-of-Life-Score.php. Accesed 12 Dec 2019

28. Lopez-Monclus J, Artes M, Gonzalez J, Blazquez LA, Lucena JL, Robin A et al (2019) Failure of talc seromadesis for the treatment of subcutaneous chronic seromas after incisional hernia surgery. Scand J Surg. https://www.ncbi.nlm.nih.gov/pubmed/31830877

29. Celdran A, GarciaUrena MA, Bazire P, Marijuan JL (1996) The use of omentum in mesh repair of ventral hernias. Am Surg 62(6):443-445

30. Winder JS, Majumder A, Fayezizadeh M, Novitsky YW, Pauli EM (2018) Outcomes of utilizing absorbable mesh as an adjunct to posterior sheath closure during complex posterior component separation. Hernia 22(2):303-309

31. Garcia-Urena MA L-MJ, Sanchez A, Blazquez LA, Robin A, Melero D, Cruz A, Lopez P, Palencia N, Gonzalez E (2015) Transversus abdomens release for a complex abdominal wall reconstruction: CineMed. https://cine-med.com/index .php?id=ACS-4038. Accessed 12 Dec 2019

32. Baumann DP, Butler CE (2013) Soft tissue coverage in abdominal wall reconstruction. Surg Clin N Am 93(5):1199-1209

33. Park SH, Eun SC (2018) Abdominal wall transplant surgery. Exp Clin Transplant 16(6):745-750

34. Eickhoff R, Guschlbauer M, Maul AC, Klink CD, Neumann UP, Engel $\mathrm{M}$ et al (2019) A new device to prevent fascial retraction in the open abdomen - proof of concept in vivo. BMC Surg 19(1):82

35. Eucker D, Zerz A, Steinemann DC (2017) Abdominal wall expanding system obviates the need for lateral release in giant incisional hernia and laparostoma. Surg Innov 24(5):455-461

36. Lipman J, Medalie D, Rosen MJ (2008) Staged repair of massive incisional hernias with loss of abdominal domain: a novel approach. Am J Surg 195(1):84-88

37. Diaz JJ, Conquest AM, Ferzoco SJ, Vargo D, Miller P, Wu YC et al (2009) Multi-institutional experience using human acellular dermal matrix for ventral hernia repair in a compromised surgical field. Arch Surg 144(3):209-215

38. Jin J, Rosen MJ, Blatnik J, McGee MF, Williams CP, Marks J et al (2007) Use of acellular dermal matrix for complicated ventral hernia repair: does technique affect outcomes? J Am Coll Surg 205(5):654-660

39. Blatnik J, Jin J, Rosen M (2008) Abdominal hernia repair with bridging acellular dermal matrix — an expensive hernia sac. Am J Surg 196(1):47-50

40. Cavalli M, Bruni PG, Lombardo F, Morlacchi A, Andretto Amodeo C, Campanelli G (2019) Original concepts in anatomy, abdominal-wall surgery, and component separation technique and strategy. Hernia. https://doi.org/10.1007/s10029-019-02030-7

Publisher's Note Springer Nature remains neutral with regard to jurisdictional claims in published maps and institutional affiliations. 